\title{
Sensores de visión aplicados a una mano biomimética
}

\author{
Vision sensors applied to a biometric hand
}

ㅁㅁ뭄

Jordi Torner, Francesc Alpiste, Miguel Brigos

Universitat Politècnica de Catalunya (España)

\section{DOI: http://dx.doi.org/10.6036/8422}

gías: la fabricación por adicción de material (Impresión 3D), la programación de una placa Arduino y la implementación y programación de sensores de visión y biomecánicos para la captación de movi- principales nervios del brazo del paciente para dotar de sensibilidad, cambiando el cableado de las fibras nerviosas para controlar prótesis más, por ejemplo, o mejorando las interfaces cerebrales para

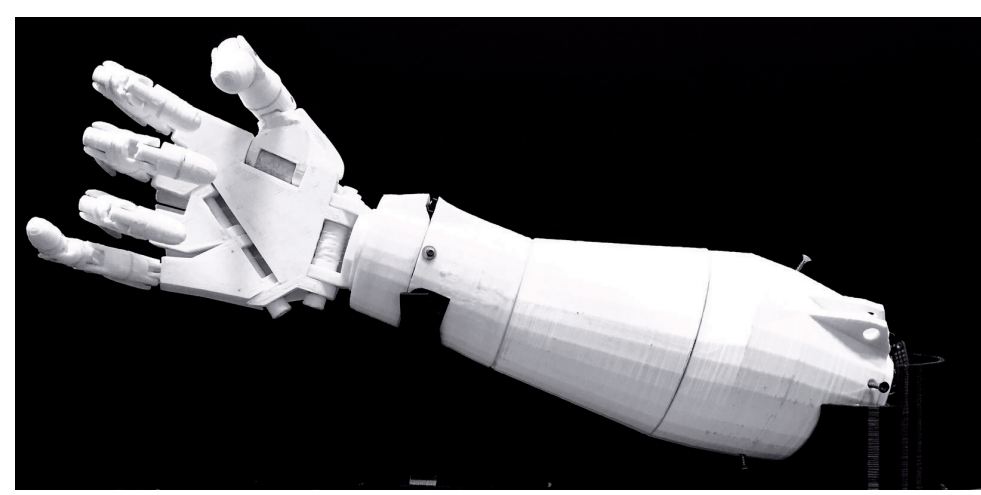

Existe un interés creciente en la exploración de soluciones de bajo coste para controles en dispositivos biomecánicos. Existen numerosos antecedentes de brazos y manos biónicas que utilizan desarrollos tecnológicos y biomédicos avanzados [13]. Los brazos controlados por implantes cerebrales o por la actividad nerviosa de la base del brazo que trasmite las órdenes de movimiento desde el cerebro a los servomotores que accionan los dedos y la muñeca y cuyos movimientos se ajustan con sensores de presión, temperatura y contacto. En este trabajo se plantea la construcción de un brazo biónico biomimético de bajo coste, accionado a partir de sensores de movimiento y de electromiografía (EGM). Los captadores de movimiento propuestos no son invasivos, por lo que no requieren implantes quirúrgicos. El sensor de visión Leap Motion es un pequeño dispositivo de sobremesa que incorpora dos cámaras. La pequeña modificación del punto de vista que ofrecen las cámaras permite la reproducción tridimensional de la imagen de la mano del operario y su posterior análisis para poder accionar un brazo robótico. La mano se construye mediante impresión 3D, que sea capaz de seguir los movimientos captados de una mano real. La mano robótica empleada para realizar este proyecto es el denominado BIONI$\mathrm{CO}$, extraído de la iniciativa InMoove [2] de Gael Langevin. Se basa en la creación de un robot humanoide a escala real, fabricado a partir de una impresora 3D. Para ello, se utilizan diferentes tecnolo- mientos. Se exploran diferentes soluciones de sensores basados en visión y electromiograma existentes en el mercado. Leap Motion cuenta con tres piezas fundamentales: las cámaras, los LEDs y el micro controlador. Las dos cámaras son una pieza clave puesto que son las encargadas de capturar las imágenes. Éstas tienen un sensor monocromático sensible a la luz infrarroja con longitud de onda $850 \mathrm{~nm}$. Este sensor alcanza una velocidad de trabajo de $100 \mathrm{fps}$. Las cámaras disponen de un sensor CMOS que está compuesto por celdas. Esto permite además de una mayor velocidad de procesado y menor coste, reducir el tamaño del dispositivo notablemente con respecto a los sensores CCD. La precisión promedio general del controlador se sitúa en torno a los 0,7 milímetros, siendo la resolución del dispositivo mayor que en Kinect de Microsoft. El controlador puede realizar tareas como navegar por un sitio web, utilizando los gestos de pellizcar para hacer zoom en mapas de alta precisión y manipulación de escenas en 3D. Esta solución puede abrir nuevas posibilidades en aplicaciones de ayuda a personas con movilidad reducida. En los entornos de aplicación, una de las posibles aplicaciones es el control a distancia a partir de los brazos del usuario. Otro entorno de aplicación sería ayudar a los discapacitados mediante el control del brazo biónico a partir de un brazo hábil. Existen diversas iniciativas en este campo que pretenden mejorar el control de las prótesis insertando electrodos en los permitir el control con el pensamiento. La mano fue presentada en la Innovation Week de Oslo y en The 22nd MMVR (Medicine Meets Virtual Reality) de Los Ángeles en 2016. En estos eventos se reconoció el interés del prototipo y su potencialidad como una solución funcional y de bajo coste.

\section{REFERENCIAS}

[1] Jessica Stoller-Conrad. Controlling a Robotic Arm with a Patient's Intentions [en línea]. [California, USA]: California Institute of Technology, may 2015 [ref. de 25 noviembre 2016]. Disponible en Web <https://www. caltech.edu/news/controlling-robotic-armpatients-intentions-46786>

[2] Johanna Wilde. World's first implanted bionic arm on test in global competition [en línea]. [Göteborg,Sweden]: Chalmers University of Technology, October 2016 [ref de 15 octubre 2016]. Disponible en Web <http://www. chalmers.se/en/departments/s2/news/Pages/ World\%E2\%80\%99s-first-implanted-bionicarm-on-test-in-global-competition-.aspx>

[3] Paulette Campbell. Modular Prosthetic Limb [en linea]. [Maryland,USA]: The Johns Hopkins University Applied Physics Laboratory LLC, 201? [ref. de 15 octubre 2016]. Disponible en Web <http://www.jhuapl.edu/prosthetics/ scientists/mpl.asp>

[4] Weichert, Frank; Bachmann, Daniel; Rudak, Bartholomäus; Fisseler, Denis (2013-05-14). "Analysis of the Accuracy and Robustness of the Leap Motion Controller". Sensors (Basel, Switzerland). 13 (5): 6380-6393. doi:10.3390/ s130506380. ISSN 1424-8220.

\section{AGRADECIMIENTOS}

Este proyecto se ha realizado en colaboración con la empresa VISYON 360. 